ВАСИЛЬЕВА Елена Игоревна - кандидат социологических наук, доцент кафедры регионального и муниципального управления Уральского института управления - филиала Российской академии народного хозяйства и государственной службы при Президенте РФ (620144, Россия, г. Екатеринбург, ул. 8-го Марта, 66, каб. 523; vasilyeva-ekb@yandex.ru)

ЗЕРЧАНИНОВА Татьяна Евгеньевна - кандидат социологических наук, заведующий кафедрой регионального и муниципального управления Уральского института управления - филиала Российской академии народного хозяйства и государственной службы при Президенте РФ (620144, Россия, г. Екатеринбург, ул.8го Марта, 66, каб. 523; zerchaninova-te@ranepa.ru)

\title{
МОТИВЫ И ЦЕННОСТНЫЕ ДОМИНАНТЫ ПРОТЕСТОВ В ОЦЕНКАХ ЛИДЕРОВ ПРОТЕСТНЫХ АКЦИЙ И МОЛОДЕЖИ
}

\begin{abstract}
Аннотация. Рост протестной активности молодежи является одной из ключевых задач, требующих решения в целях обеспечения устойчивости политической системы государства. В статье представлены результаты всероссийского анкетного опроса молодежи и интервью с лидерами протестных акций. Участие в акциях протеста обусловлено идеологическими установками молодежи, потребностью в принадлежности к социальной группе, отсутствием институционализированных каналов влияния на принятие решений, высоким уровнем коррупции, кризисом власти. По мнению экспертов, в акциях протеста скорее выражаются фундаментальные ценности и видение молодежью идеального будущего.
\end{abstract}

Ключевые слова: молодежь, протест, политическая активность, протестная активность, ценности, ценностные доминанты

Введение. Протестная активизация, в т.ч. молодежи во всем мире, привела к научной дискуссии о драйверах, лежащих в ее основе. Исследователи считают, что проблемные ситуации в значительной степени не являются объективными, а представляют собой скорее символические реалии, артикулированные посредством аксиологической конвергенции [Vasquez 1994]. Иначе говоря, именно в процессе социального взаимодействия происходит обсуждение, интерпретация тех или иных событий на основе ценностей. Во многом данное обстоятельство может объяснить развитие протестных форм в социальных сетях, а также скептические оценки участниками результативности протестной активности. Согласно результатам исследования J.N. Kim и др., осознание проблемы, ее рационализация, артикуляция не имеют значительной связи с мотивацией или участием в протесте [Kim et al. 2012], напротив, индивиды вовлекаются в протестные формы посредством эмоций. Именно эмоционально обусловленные драйверы могут рассматриваться как ведущие в запуске активных действий, поскольку рациональный человек никогда не стал бы участвовать в коллективном действии из-за временных, финансовых, физических и психологических затрат [Stekelenburg, Klandermans 2013].

Ряд авторов полагают, что сдвиг в способах политической активности обусловлен изменением политических ценностей: модернизация общества ведет к трансформации ценностных ориентаций, способствуя увеличению внеинституциональных политических действий [Dalton, Van Sickle, Weldon 2010].

Анализируя научные исследования, посвященные драйверам протестной активности, можно выделить три основных причины активизации данной формы участия. Первая группа аксиологических детерминант протестной активности связана с достижением общественной пользы или общественного блага для всего общества, несмотря на то, сколько человек участвует в проте- 
сте. Например, успешный протест за сохранение парка приносит пользу всем, хотя некоторые горожане не протестовали.

Вторая группа мотивов (социальных) сопряжена с потребностями в социальной принадлежности и ожидаемой реакцией значимых других (например, членов семьи, друзей или коллег) на участие человека в данном коллективном действии.

Третья группа драйверов связана с ожиданием вознаграждения (какоголибо) за участие в протестной активности. При этом происходит сопоставление затрат (например, физический риск, время или деньги) и выгоды, которую получит участник от участия в акции протеста. Например, люди, участвующие в протесте, могут терять время и силы, но получать удовольствие от общения с другими участниками, разделяющими их взгляды [Kim 2018].

Тематика протестной активности современной российской молодежи достаточно актуальна среди российских исследователей [Бродовская, Хуанг 2019; Щебланова и др. 2020; Коротаев и др. 2021]. Несмотря на дискуссию о мотивах участия в протестах, исследование ценностных детерминант протестной активности практически не представлено в научной литературе, поэтому необходимо рассмотреть, как влияют различные ценностные ориентации на готовность к участию и организации протестных акций и какие из них лежат в основе протестной активности современной российской молодежи.

Исходя из этого, исследовательские вопросы могут быть сформулированы следующим образом:

1) каково отношение современной российской молодежи к протестной активности?

2) каков уровень готовности современной российской молодежи к участию в акциях протеста?

3) какие ценности лежат в основе протестной активности современной российской молодежи?

В основе методологии исследования лежит сочетание качественной и количественной стратегий. Объектами эмпирического исследования являются российская молодежь в возрасте от 14 до 35 лет и лидеры протестных акций.

В июле 2021 г. при участии авторов был проведен всероссийский опрос молодежи в возрасте от 14 до 35 лет. Во всех федеральных округах РФ опрошены 2302 чел. В августе 2021 г. были проведены интервью с лидерами протестных акций. Опрошены 15 респондентов. Активисты протестов были отобраны на основе упоминаний Telegram-каналов и согласились дать комментарии по результатам опроса молодежи и причин участия в протестах на условиях полной анонимности.

Результаты исследования. Согласно полученным данным, только 7,6\% молодежи не слышали об акциях протеста в стране, при этом 68,2\% респондентов считают, что они знают о причинах протестной активности. Полученные результаты свидетельствуют о высоком уровне информированности о протестной активности, вовлечении и внимании к данной теме.

Лидеры протестных акций согласились с полученными данными. По их мнению, не зная точной причины того или иного выступления, митинга, молодежь их рассматривает прежде всего в контексте защиты демократических ценностей, кризиса действующей власти и решения социально-экономических проблем. При этом лидеры протестных акций считают, что сама проблема, являющаяся поводом к выступлению, отходит на второй план, поскольку важнее именно символический аспект самого протеста, желание «продемонстрировать власти, что есть мы». Также лидеры протестных акций связали высокую информированность молодежи о протестах с предпочитаемыми каналами 
получения информации: молодежь серьезным образом отличается от лиц среднего и пожилого возраста, поскольку практически не смотрит телевизор, а информацию черпает из социальных сетей, пабликов и пр.

Это подтверждается результатами опроса: 44,3\% респондентов не принимали участия в протестных мероприятиях, однако большинство опрошенных указали, что участвовали в обсуждении политических вопросов в социальных сетях $(25,2 \%)$, ставили лайки и делали репосты протестного контента $(22,5 \%)$, подписывали онлайн-обращения, петиции (24\%), вступали в группы, обсуждающие проблемы в стране (19,2\%) (см. табл. 1).

Таблица 1

Принимали ли Вы участие в следующих мероприятиях за последние 3 года?

\begin{tabular}{|l|c|}
\hline \multicolumn{1}{|c|}{ Варианты ответов } & Доля опрошенных, \\
\hline \multicolumn{1}{|c|}{} & 9,1 \\
\hline Участвовал в митингах, демонстрациях, пикетах & 3,5 \\
\hline Участвовал в забастовках & 7,7 \\
\hline $\begin{array}{l}\text { Организовывал группы волонтеров и добровольцев для участия в } \\
\text { акциях протеста }\end{array}$ & 8,0 \\
\hline Собирал подписи на обращениях, петициях & 24,0 \\
\hline Подписывал обращения, петиции, в т.ч. онлайн-петиции & 22,5 \\
\hline $\begin{array}{l}\text { Ставил лайки и делал репосты протестного контента в социальных } \\
\text { сетях }\end{array}$ & 25,2 \\
\hline $\begin{array}{l}\text { Участвовал в обсуждении политических вопросов в социальных } \\
\text { сетях, мессенджерах }\end{array}$ & 19,2 \\
\hline $\begin{array}{l}\text { Онлайн-подписка на социально-политические паблики, } \\
\text { сообщества, обсуждающие проблемы в стране }\end{array}$ & 14,3 \\
\hline $\begin{array}{l}\text { Онлайн-подписка на социально-политические паблики, } \\
\text { сообщества оппозиционных политических сил }\end{array}$ & 44,3 \\
\hline Участие в подобных мероприятиях за последний год не принимал & 0,1 \\
\hline Другое & - \\
\hline
\end{tabular}

Таким образом, большая часть молодежи за последние три года принимала участие в различных мероприятиях, которые можно отнести к протестной активности, причем большая часть такой активности осуществлялась онлайн. В акциях протеста, которые проходили не в сети, принимали участие только $12,6 \%$ опрошенных. Таким образом, в сети формируется нарратив, смысловое поле, которое разделяют многие молодые люди.

Для анализа связи между потребностью в социальной принадлежности и протестной активностью респондентам был задан вопрос об участии их знакомых в реальных протестных акциях. Большинство респондентов $(57,4 \%)$ отметили, что среди их знакомых есть те, кто участвовал в реальных протестных акциях за последние 3 года.

Такая высокая доля респондентов, в кругу знакомых которых есть участники протестов, может свидетельствовать о высоком потенциале вовлечения в реальные протесты молодежи в случае разворачивания кампаний по мобилизации участников протестов. Такие результаты связаны и со спецификой моло- 
дежи как социальной группы, ее диспозицией, а также со значительной долей онлайн-активности современной молодежи.

В этой связи интересно обратиться к анализу причин неучастия в протестной активности. Согласно полученным данным, для тех, кто не принимает участия в реальных или виртуальных акциях протеста, характерны пессимистические оценки такого рода мероприятий: «не верю, что мое участие в акциях протеста может что-то реально изменить в стране» $(17,8 \%)$; «опасаюсь возникновения проблем на работе, учебе» $(12,9 \%)$ и оказаться «под арестом, получить штраф» $(9,2 \%)$; «лучше использовать другие способы выражения своего недовольства» $(13,5 \%)$. Вместе с тем обращает на себя внимание, что $15,4 \%$ респондентов, которые не участвуют в акциях протеста, не делают этого из-за неприятия сил, которых их организуют (см. табл. 2).

Таблица 2

Если Вы не принимали участие в реальных или виртуальных акциях протеста, то почему?

\begin{tabular}{|c|c|}
\hline Варианты ответов & $\begin{array}{l}\text { Доля опрошенных, } \\
\%\end{array}$ \\
\hline Опасаюсь, что у меня могут возникнуть проблемы на работе/учебе & 12,9 \\
\hline $\begin{array}{l}\text { Опасаюсь, что меня могут заключить под стражу, наложить } \\
\text { крупный штраф }\end{array}$ & 9,2 \\
\hline Опасаюсь, что меня будут ругать и критиковать родители, близкие & 5,7 \\
\hline $\begin{array}{l}\text { Не верю, что мое участие в акциях протеста может что-то реально } \\
\text { изменить в стране }\end{array}$ & 17,8 \\
\hline Не поддерживаю силы, которые организуют такие акции & 15,4 \\
\hline $\begin{array}{l}\text { Считаю, что лучше использовать другие способы выражения } \\
\text { своего недовольства }\end{array}$ & 13,5 \\
\hline $\begin{array}{l}\text { Не считаю важными те поводы, по которым проводятся такие } \\
\text { акции }\end{array}$ & 8,7 \\
\hline Другое & 0,9 \\
\hline Не вижу смысла & 0,5 \\
\hline Затрудняюсь ответить & 15,4 \\
\hline Всего: & 100,0 \\
\hline
\end{tabular}

Анализ мнения респондентов относительно причин протестной активности показывает, что молодежь не видит других способов выразить недовольство $(46,3 \%)$, считает необходимым отстаивать свои позиции и их артикуляцию $(44,2 \%)$ из убеждений $(31 \%)$, ради популярности $(20,7 \%)$ и за компанию $(20,7 \%)$ (см. табл. 3).

Таким образом, потребность в социальной принадлежности, которую испытывает часть молодежи, может быть одним из драйверов протестной активности. Однако обращает на себя внимание отсутствие иных механизмов влияния на власть, низкий социальный капитал молодежи, отсутствие, по мнению молодежи, механизмов донесения своей позиции.

Последнее обстоятельство коррелирует и с мотивами протестной активности молодежи: это бюрократия, коррупция (35\%); кризис власти $(27,2 \%)$; материальные трудности $(31,4 \%)$; проблемы внутренней политики $(29,2 \%)$; плохая 
Таблица 3

Как Вы думаете, почему молодежь участвует в протестах?*

\begin{tabular}{|l|c|}
\hline \multicolumn{1}{|c|}{ Варианты ответов } & Доля опрошенных, \\
\hline Из чувства солидарности & 12,5 \\
\hline Чтобы высказать/отстоять свою позицию & 44,2 \\
\hline Чтобы заработать себе популярность, хайп & 20,7 \\
\hline Ради денег & 11,3 \\
\hline За компанию с друзьями & 20,7 \\
\hline Из политических, идеологических убеждений & 31,0 \\
\hline Чтобы интересно провести время, разнообразить впечатления & 12,6 \\
\hline Молодежь не видит других способов выразить свое недовольство & 46,3 \\
\hline Затрудняюсь ответить & 11,6 \\
\hline Другое & 0,7 \\
\hline
\end{tabular}

* Можно выбрать не более 3 вариантов ответов.

социальная поддержка (25\%); жесткий контроль общественной жизни $(21,1 \%)$ и в жесткий контроль в Интернете $(18,4 \%)$ (см. табл. 4).

Таким образом, протест мотивирован политическими и экономическими проблемами. Большинство респондентов едины в идентификации причин протестной активности.

По мнению лидеров протестных акций, участие в протестах имеет символический аспект, вызвано невозможностью иначе донести свою позицию, социально-экономическими трудностями молодежи. Один из экспертов отметил, что «без их коллективных действий события нет, оно не было бы освещено репортерами. Это был лучший способ привлечь внимание к проблеме».

По мнению опрошенных экспертов, протест - это единственный канал коммуникации с властью, в частности с президентом. Он используется как механизм обратной связи. Эксперты называют иные механизмы согласования интересов и обратной связи полностью бесполезными. По их мнению, «единственный прямой способ выразить свое мнение - это голосование, но это не вариант в текущей ситуации».

Эксперты также связывают мотивы выхода молодежи на улицу с негативными эмоциями, такими как потери, разочарование, стыд, негодование, беспокойство, уныние или бессилие. Так, один из экспертов объяснил: «Этот протест представляет собой эмоциональную разрядку для граждан. <...> Эмоции некоторых участников не имели никакого отношения к проблемам, вызвавшим протест».

Обращает на себя внимание, что эксперты так же, как и молодежь в целом, сомневаются в эффективности таких протестов, но свое участие они объясняют надеждами на изменение ситуации, т.е. организаторы ждут реакции со стороны власти на свои в значительной степени символические акции. Один из экспертов отметил: «Я не думаю, что наше участие определит возможность решения проблемы, но мы надеемся внести свой вклад... потому что, если к 
Таблица 4

Как Вы думаете, чем недовольна молодежь, которая участвует в акциях протеста, митингах, демонстрациях?

\begin{tabular}{|l|c|}
\hline \multicolumn{1}{|c|}{ Варианты ответов } & Доля опрошенных, \\
\hline Проблемы внутренней политики страны & 29,2 \\
\hline Сложности в поиске хорошей работы, ведении бизнеса & 20,2 \\
\hline Бюрократия и коррупция власти & 35,4 \\
\hline Кризис действующей власти & 27,2 \\
\hline Жесткий контроль общественной жизни властными органами & 21,1 \\
\hline Жесткий контроль свободы слова в Интернете & 18,4 \\
\hline Ослабление воспитательной работы в школах, вузах & 10,1 \\
\hline $\begin{array}{l}\text { Отсутствие досуга для молодежи, доступных спортивных и } \\
\text { творческих кружков и секций }\end{array}$ & 13,9 \\
\hline Материальные трудности современной молодежи & 31,4 \\
\hline $\begin{array}{l}\text { Снижение в целом культурного уровня современной молодежи, } \\
\text { размывание морально-нравственных ценностей }\end{array}$ & 14,1 \\
\hline Плохая социальная поддержка молодежи, молодых семей & 25,0 \\
\hline Затрудняюсь ответить & 9,7 \\
\hline Все вышеперечисленное & 0,1 \\
\hline Другое & 0,3 \\
\hline
\end{tabular}

протесту присоединится много людей, президент может понять, чего люди действительно хотят, и я думаю, мы покажем им, чего хотим».

Оценивая потенциал протестной активности молодежи, рассмотрим отношение молодежи к протестным акциям. Несмотря на то что каждый третий респондент относится к протестам безразлично $(35,4 \%)$, a $13,2 \%$ респондентов хотят разогнать выступающих, каждый пятый респондент $(22,4 \%)$ испытывает желание участвовать в этих выступлениях (см. табл. 5).

Аналогичные результаты были получены и при ответе на вопрос о возможности присоединиться к акции протеста. Каждый пятый $(20,3 \%)$ выражает готовность присоединиться к реальной акции протеста в его городе (населенном пункте) (см. табл. 6).

Все это свидетельствует о высоком мобилизационном потенциале протестной активности молодежи, существенно сдерживаемом только отсутствием веры в позитивные результаты, страхом наказания и недоверием к организаторам акций.

Потенциально готовы участвовать в протестах $57 \%$ респондентов. Наиболее важные мотивы участия в реальных акциях протеста для молодых россиян это экономические, политические (учет мнения граждан при принятии решений) и экологические проблемы (см. табл. 7).

Можно констатировать, что одним из факторов протестной активности молодежи является потребность в социальной принадлежности. Вместе с тем распространенность в среде российской молодежи крупных городов индиви- 
Таблица 5

Что Вы испытываете, наблюдая в Интернете за протестными выступлениями?

\begin{tabular}{|l|c|}
\hline \multicolumn{1}{|c|}{ Варианты ответов } & Доля опрошенных, \\
\hline Хочется только посмотреть, но не участвовать & 18,3 \\
\hline Испытываю желание поучаствовать в этих выступлениях & 22,4 \\
\hline Хочется разогнать этих выступающих & 13,2 \\
\hline Отношусь безразлично & 35,4 \\
\hline Затрудняюсь ответить & 10,7 \\
\hline Всего: & 100,0 \\
\hline
\end{tabular}

Таблица 6

Если в Вашем городе (населенном пункте) состоятся акции протеста, митинги или демонстрации, Вы лично примете в них участие?

\begin{tabular}{|l|c|}
\hline \multicolumn{1}{|c|}{ Варианты ответов } & Доля опрошенных, \% \\
\hline Да, обязательно & 5,8 \\
\hline Скорее всего приму участие & 14,5 \\
\hline Скорее всего не приму & 35,4 \\
\hline Нет, не приму & 32,8 \\
\hline Затрудняюсь ответить & 11,5 \\
\hline Всего: & 100,0 \\
\hline
\end{tabular}

Таблица 7

Если Вы готовы принять участие в акции протеста, митинге или демонстрации, то по каким проблемам?

\begin{tabular}{|l|c|}
\hline \multicolumn{1}{|c|}{ Варианты ответов } & $\begin{array}{c}\text { Доля опрошенных, } \\
\text { \% }\end{array}$ \\
\hline $\begin{array}{l}\text { Политические вопросы (участие в выборах отдельных кандидатов, } \\
\text { подсчет голосов и т.п.) }\end{array}$ & 12,9 \\
\hline Оппозиционные политические митинги & 12,9 \\
\hline $\begin{array}{l}\text { Экономические вопросы (снижение доходов, экономический } \\
\text { кризис, падение уровня жизни) }\end{array}$ & 34,8 \\
\hline $\begin{array}{l}\text { Вопросы взаимодействия власти и общества (учет мнения } \\
\text { населения при принятии решений, насилие со стороны силовиков } \\
\text { и пр.) }\end{array}$ & 25,6 \\
\hline $\begin{array}{l}\text { Экологические вопросы (размещение на территории города или } \\
\text { рядом с вашим домом вредного производства, свалки и т.п.) }\end{array}$ & 24,0 \\
\hline Митинг по национальным вопросам, против мигрантов & 7,8 \\
\hline Вопросы ущемления прав & 11,9 \\
\hline Обманутые дольщики, ЖКХ, уплотнительная застройка & 6,3 \\
\hline Недовольство социальной политикой государства & 11,8 \\
\hline Я не готов принять участие в акции протеста & 43,0 \\
\hline
\end{tabular}


дуалистических материальных ценностей и экономических интересов также может быть использована в рамках мобилизации протестного потенциала (см. табл. 8).

Таблица 8

Каковы Ваши самые важные жизненные ценности?

\begin{tabular}{|c|c|}
\hline Варианты ответа & $\begin{array}{c}\text { Доля опрошенных, } \\
\% \\
\end{array}$ \\
\hline Стремление иметь интересную и высокооплачиваемую работу & 31,1 \\
\hline Стать хорошим специалистом & 13,6 \\
\hline Занять соответствующее положение в обществе & 12,6 \\
\hline Приобрести желаемую профессию, специальность & 14,4 \\
\hline Жить и работать среди образованных и культурных людей & 21,9 \\
\hline Добиться лучшей материальной обеспеченности & 31,4 \\
\hline Стать полезным обществу и своей стране & 15,8 \\
\hline Получить «легкую» и прибыльную работу & 10,0 \\
\hline Семейное счастье & 34,8 \\
\hline Здоровье свое и близких & 52,2 \\
\hline Качественное образование & 7,1 \\
\hline Карьера & 12,3 \\
\hline Спокойная жизнь & 14,8 \\
\hline Удовлетворенность достигнутым & 10,1 \\
\hline Развлечения & 3,7 \\
\hline Свобода и независимость & 12,6 \\
\hline Добиться всего честным трудом & 5,6 \\
\hline Общественное признание, уважение и почет & 5,2 \\
\hline Затрудняюсь ответить & 2,0 \\
\hline
\end{tabular}

Заключение. Полученные в ходе эмпирического исследования результаты позволяют сделать вывод, что участие в акциях протеста для современной российской молодежи предполагает проявление не только идеологических установок, но и потребности в принадлежности к социальной группе. По мнению каждого пятого респондента, молодежь участвует в протестных акциях за компанию. Однако протестное поведение сопряжено и с отсутствием институционализированных каналов влияния на принятие решений, с мнением о высоком уровне коррупции и оценкой молодежью происходящих политических процессов как кризиса власти. Обращает на себя внимание значимость материального достатка при низкой значимости качественного образования и общественного признания.

Несмотря на доминирование в ценностно-смысловой подструктуре личности утилитарных и материальных мотивов, по мнению экспертов, в акциях протеста скорее выражаются фундаментальные ценности и видение идеального будущего молодежью. В экспертном интервью наиболее часто используемыми фреймами были «надежда», «будущее». Иными словами, протест вос- 
принимается не как ситуативная активность, а как «долгосрочная стратегия обретения политического голоса молодежью».

Исследование выполнено при финансовой поддержке РФФИ и ЭИСИ в рамках научного проекта № 21-011-31682.

\section{Список литературы}

Бродовская Е.В., Хуанг Т. 2019. Цифровое поколение: гражданская мобилизация и политический протест российской молодежи. - Мониторинг общественного мнения: экономические и социальные перемены. № 5(153). С. 3-18.

Коротаев А., Сойер П., Гладышев М., Романов Д., Шишкина А. 2021. О некоторых социально-демографических факторах интенсивности антиправительственных демонстраций: доля молодежи в населении, урбанизация и протесты. - Социологическое обозрение. Т. 20. № 3. С. 98-128.

Щебланова В.В., Логинова Л.В., Зайцев Д.В., Суркова И.Ю. 2020. Гражданский активизм студентов: риск деструктивных проявлений в Поволжском регионе. - Вестник Российского университета дружкбы народов. Сер. Социология. № 3. C. 595-610.

Dalton R.J., Van Sickle A., Weldon S. 2010. The Individual-Institutional Nexus of Protest Behaviour. - British Journal of Political Science. Vol. 40. No. 1. P. 51-73.

Kim J. 2018. Why Do People Take to the Streets? Understanding the Multidimensional Motivations of Protesting Publics. - Public Relations Review. Vol. 44. Is. 4. P. 501-513.

Kim J.N., Ni L., Kim S.H., Kim J.R. 2012. What Makes People Hot? Applying the Situational Theory of Problem Solving to Hot-issue Publics. - Journal of Public Relations Research. Vol. 24. Is. 2. P. 144-164.

Stekelenburg J., Klandermans B. 2013. The Social Psychology of Protest. - Current Sociology. Vol. 61. No. 5-6. P. 886-905.

Vasquez G.M. 1994. Testing a Communication Theory-Method-Message Behavior Complex for the Investigation of Publics. - Journal of Public Relations Research. Vol. 6. Is. 4. P. 267-291. 
VASIL'EVA Elena Igorevna, Cand.Sci. (Soc.), Associate Professor of the Chair of Regional and Municipal Management, Ural Institute of Management - Branch of the Russian Presidential Academy of National Economy and Public Administration (RANEPA) (room 523, 66 March 8 St, Ekaterinburg, Russia, 620144; vasilyeva-ekb@yandex.ru)

ZERCHANINOVA Tatiana Evgen'evna, Cand.Sci. (Soc.), Associate Professor; Head of the Chair of Regional and Municipal Management, Ural Institute of Management - Branch of the Russian Presidential Academy of National Economy and Public Administration (RANEPA) (room 523, 66 March 8 St, Ekaterinburg, Russia, 620144; zerchaninova-te@ ranepa.ru)

\title{
THE MOTIVES AND VALUE DOMINANTS OF PROTESTS IN ASSESSMENTS OF LEADERS OF PROTEST ACTIONS AND YOUTH
}

\begin{abstract}
The growth of the protest activity of the Russian youth is one of the key tasks that needs addressing to in order to ensure the stability of the political system of the state. The purpose of the work is to consider the influence of various value orientations of young people on the willingness to participate and organize protest actions. The article presents the results of an all-Russian questionnaire survey of young people aged from 14 to 35 on the problem of protest activity and protest potential. 2302 respondents were interviewed by the method of questioning. In addition, 15 interviews were conducted with the leaders of the protest actions that took place in Russia with the participation of young people. The results obtained during the empirical study allow us to conclude that participation in protest actions for modern Russian youth involves the manifestation of not only ideological attitudes, but also the need to belong to a social group. According to every fifth respondent, young people participate in protest actions for company. However, protest behavior is also associated with the lack of institutionalized channels of influence on decision-making, with an opinion about a high level of corruption and young people's assessment of ongoing political processes as a crisis of power. The authors draw attention to the importance of material wealth with the low importance of quality education and public recognition. According to experts, protests rather express fundamental values and the vision of an ideal future by young people. In other words, the protest is perceived not as a situational activity, but as a long-term strategy for gaining a political voice for young people.

Keywords: youth, protest, political activity, protest activity, values, value dominants
\end{abstract}

